\title{
4-Halo-1,3-oxazoles: Unambiguous structural assignment of 2-halo-2-benzoyl-2H-azirine-3-carboxylates thermal ring expansion products
}

\author{
Susy Lopes, Cláudio M. Nunes, Rui Fausto, Teresa M.V.D. Pinho e Melo* \\ Department of Chemistry, University of Coimbra, P-3004-535 Coimbra, Portugal
}

\section{A R T I C L E I N F O}

\section{Article history:}

Received 17 July 2008

Received in revised form 7 August 2008

Accepted 8 August 2008

Available online 26 August 2008

Keywords:

Ring expansion

Matrix isolation FTIR spectroscopy

$2 \mathrm{H}$-Azirines

1,3-Oxazoles

Isoxazoles

\begin{abstract}
A B S T R A C T
IR spectroscopy in cryogenic argon matrix of methyl 4-chloro-5-phenyl-1,3-oxazole-2-carboxylate and methyl 4-chloro-5-phenylisoxazole-3-carboxylate was applied for the structural assignment of these isomeric heterocycles. It was demonstrated that methyl 2-benzoyl-2-halo-2H-azirine-3-carboxylates undergo thermal ring expansion to give 4-halo-5-phenyl-1,3-oxazole-2-carboxylates and not the isomeric isoxazoles.
\end{abstract}

(c) 2008 Elsevier B.V. All rights reserved.

\section{Introduction}

Oxazoles and isoxazoles are isomeric heterocyclic compounds having a remarkable number of applications and have been demonstrated to be very versatile building blocks in organic synthesis [1]. The wide range of biological activities of isoxazoles and oxazoles includes pharmacological properties such as hypoglycemic, analgesic, anti-inflammatory, anti-bacterial, anti-tumoral and HIV-inhibitory activity. Some isoxazole derivatives display agrochemical properties, namely herbicidal and soil fungicidal activity, and have applications as pesticides and insecticides. Isoxazoles have also been used as dyes, electric insulating oils, high temperature lubricants and polyisoxazoles have applications as semicondutors. The oxazole ring occurs naturally and the total synthesis of natural products with a wide variety of biological activities containing oxazole moiety is an area of intense research. Other applications of oxazole derivatives include the use as pesticides, fluorescent whitening agents, lubricants, dyes and pigments. Therefore, there is considerable interest of having available efficient routes to these heterocycles and to better understand their reactivity.

In relation with our ongoing research on the synthesis and reactivity of 2-halo- $2 \mathrm{H}$-azirines [2] we reported the thermolysis of 2halo-2-acyl-2H-azirines (Scheme 1) [2g]. 2-Benzoyl-2-halo-2H-azirine-3-carboxylates (1) underwent ring expansion giving products in high yield which were identified as being 4-haloisoxazoles 3.

\footnotetext{
* Corresponding author.

E-mail address: tmelo@ci.uc.pt (T.M.V.D. Pinho e Melo).
}

The same products were also obtained in high yield from the thermolysis of haloazidoalkenes 4 via intermediate 2-benzoyl-2-halo$2 \mathrm{H}$-azirines 1.

The thermolysis of $2 \mathrm{H}$-azirines usually results in cleavage of the $\mathrm{N}-\mathrm{C} 2$ single bond giving a transient vinylnitrene, the reverse of the cyclization of vinylnitrenes used to prepare $2 \mathrm{H}$-azirines [3]. Evidence for the existence of this intermediate comes from the thermal ring opening of 2,3-diaryl-2-cyano-2H-azirine where the vinylnitrene was trapped with phosphanes [4]. On the other hand, it was known that heating a solution of 3-phenyl-2H-azirine-2-carboxaldehyde (5a) at $200{ }^{\circ} \mathrm{C}$ leads to 3-phenylisoxazole (6a) in high yield [ $5 \mathrm{a}$ ]. The same isoxazole can also be obtained in $90 \%$ yield by treatment of 3-phenyl- $2 \mathrm{H}$-azirine-2-carboxaldehyde at $25{ }^{\circ} \mathrm{C}$ with Grubbs' catalyst [5b]. Furthermore, 2-benzoyl-3-phenyl-2H-azirine (5b) affords the corresponding isoxazole $\mathbf{6 b}$ upon heating in nonhydroxylic solvents $[5 \mathrm{c}]$. These observations led us to rationalize the thermal reaction of 2-benzoyl-2-halo-2H-azirine-3-carboxylates (1) as being the conversion into isoxazoles $\mathbf{3}$ via vinyl nitrenes 2 (Scheme 1).

Isoxazoles have also been obtained from ( $Z$ )- $\beta$-azido- $\alpha, \beta$-unsaturated ketones and esters (7 and 9a) (Scheme 2) [5d,5e]. Hassner et al. also observed that meso-1,2-benzoylethylene dibromide 12 reacts with two equivalents of sodium azide to give 3-benzoyl-5phenylisoxazole $\mathbf{1 3}$ via a vinyl azide intermediate [5f]. However, the thermal induced reaction of (E)- $\beta$-azido- $\alpha, \beta$-unsaturated ketone $\mathbf{9 b}$ gives the corresponding 1,3-oxazole $\mathbf{1 1}$ [5e]. The different outcome of the thermolysis of the (Z)- and (E)- $\beta$-azido- $\alpha, \beta$-unsaturated ketones led the authors to propose a concerted mechanism for the synthesis of isoxazoles starting from (Z)- $\beta$-azido- $\alpha, \beta$-unsat- 

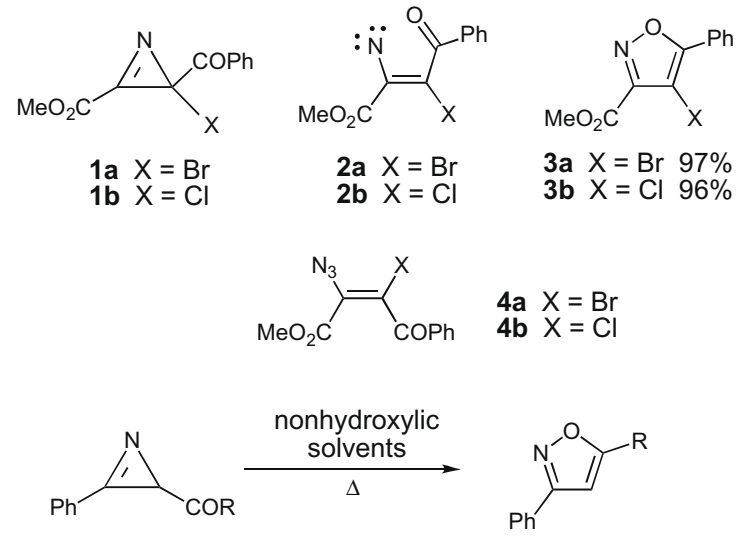

5a $\mathrm{R}=\mathrm{H} \quad 6 \mathrm{a} \mathrm{R}=\mathrm{H} \quad 80 \%$ $\begin{array}{ll}5 \text { b } R=P h & 6 \text { b } R=P h \quad 30 \%\end{array}$

Scheme 1.

urated ketones. In the case of the $(E)$ - $\beta$-azido- $\alpha, \beta$-unsaturated ketones the concerted mechanism would not be possible due to the configuration of the alkene. Therefore, the formation of $2 \mathrm{H}$-azirine intermediates was postulated followed by ring expansion reaction to oxazole, which would require a $\mathrm{C} 2-\mathrm{C} 3$ bond cleavage. These observations could lead to the conclusion that starting from 2acyl- $2 \mathrm{H}$-azirines only oxazoles could be obtained. Nevertheless, this does not account for the fact that the thermolyses of both 3phenyl-2H-azirine-2-carboxaldehyde (5a) and 2-benzoyl-3-phenyl-2H-azirine (5b) afford the corresponding isoxazoles (Scheme 1) $[5 a, 5 c]$. In fact, the reactivity pattern of $2 \mathrm{H}$-azirine derivatives has been shown to be more difficult to establish a priori then initially supposed, since it is significantly dependent on the nature of the substituents.

In fact, under thermal conditions the reactivity expected for $2 \mathrm{H}$ azirines is the cleavage of the $\mathrm{N}-\mathrm{C} 2$ single bond giving a transient vinylnitrene whereas the photolysis should lead to the cleavage of the $\mathrm{C} 2-\mathrm{C} 3$ bond giving nitrile ylide intermediates $[1,3]$. However, we have previously studied the UV induced photochemical reactions of two aliphatic $2 \mathrm{H}$-azirines - methyl 2-chloro-3-methyl$2 \mathrm{H}$-azirine-2-carboxylate and methyl 3-methyl-2H-azirine-2-carboxylate - isolated in argon matrices [6a-c]. For both compounds, irradiation with $\lambda>235 \mathrm{~nm}$ led to the observation of two primary photoprocesses: the expected $\mathrm{C} 2-\mathrm{C} 3$ bond cleavage, with production of nitrile ylides, but also the $\mathrm{N}-\mathrm{C} 2$ bond cleavage, with produc-
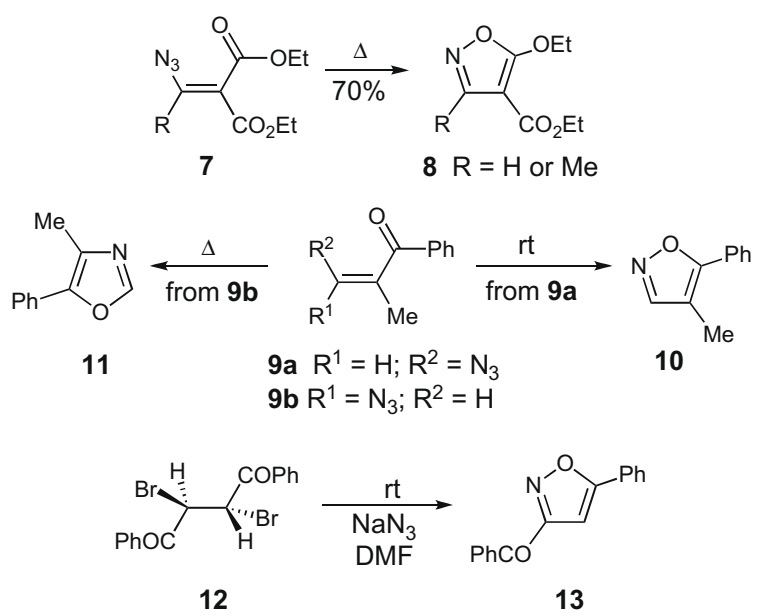

Scheme 2. tion of methylated ketene imines. Inui and Murata also demonstrated that both $\mathrm{C} 2-\mathrm{C} 3$ and $\mathrm{N}-\mathrm{C} 2$ bonds can be cleaved upon photolysis of matrix-isolated $2 \mathrm{H}$-azirines bearing an aromatic substituent at $\mathrm{C} 2[6 \mathrm{~d}, 6 \mathrm{e}]$. They concluded that the tendency toward the $\mathrm{N}-\mathrm{C} 2$ bond cleavage increases with the electron-withdrawing ability of the ring substituents.

Thermally induced ring expansion reactions of 2-acyl-2H-azirines leading to oxazoles have also been reported, although these transformations required a base- or Lewis acid-catalysis or the use of organometallic catalysts [5c,7].

Matrix isolation infrared spectroscopy is extremely powerful to undertake detailed structural and photochemical studies. Once the substance under investigation is isolated in a cryogenic inert matrix, in situ irradiation can be undertaken and the progress of the reaction probed spectroscopically. The use of criteriously chosen irradiation conditions can selectively induce a given reaction path, enabling a detailed characterization of the related intermediates. Thus, we decided to use matrix isolation infrared spectroscopy to carry out the structural and vibrational characterization as well as the study of the photochemistry of 4-haloisoxazoles.

The chloro compound obtained from the thermolysis of methyl 2-benzoyl-2-chloro-2H-azirine-3-carboxylate (1) $)$ was selected for our study. The monomeric structure isolated in low temperature argon matrix was studied by FT-IR spectroscopy, supported by theoretical calculations undertaken at the DFT(B3LYP)/6-311++G(d,p) level of theory. For our surprise the theoretically predicted spectrum for isoxazole $\mathbf{3 b}$ did not match the experimental IR spectrum. Indeed, the results described below will demonstrate that the studied compound can not be methyl 4-chloro-5-phenylisoxazole-3carboxylate (3b) but instead we are in the presence of methyl 4chloro-5-phenyl-1,3-oxazole-2-carboxylate (15) (MCPOC).

\section{Experimental}

${ }^{1} \mathrm{H}$ NMR spectra were recorded on a Bruker Avance 300 instrument operating at $300 \mathrm{MHz} .{ }^{13} \mathrm{C}$ NMR spectra were recorded on a Bruker Avance 300 instrument operating at $75.5 \mathrm{MHz}$. The solvent is deuteriochloroform except where indicated otherwise. IR spectra were recorded on a PerkinElmer 1720X FTIR spectrometer. Mass spectra were recorded on a HP GC 6890/MSD5973 instrument under electron impact (EI) except where indicated otherwise. Microanalyses were performed using an EA 1108-HNS-O Fisons instrument. Mp were recorded on a Reichert hot stage and are uncorrected. Flash column chromatography was performed with Merck 9385 silica as the stationary phase.

\subsection{General procedure for the synthesis of 1,3-oxazoles 15 and $\mathbf{1 8}$ from 2-halo-2H-azirines}

The 2-halo-2H-azirine [2b] (2.81 mmol) was dissolved in toluene $(10 \mathrm{ml})$ and the reaction mixture was heated at reflux for $5 \mathrm{~h}$. The solvent was evaporated giving the 1,3-oxazole as a solid.

\subsubsection{Methyl 4-chloro-5-phenyl-1,3-oxazole-2-carboxylate 15 [8]}

Compound 15 was obtained as a solid (96\%), mp $71-72{ }^{\circ} \mathrm{C}$. IR (KBr) 1529, 1738, $2959 \mathrm{~cm}^{-1}$; ${ }^{1} \mathrm{H}$ NMR 4.04 (3H, s), 7.47-7.51 $(3 \mathrm{H}, \mathrm{m}, \mathrm{Ar}-\mathrm{H}), 7.98-8.01(2 \mathrm{H}, \mathrm{m}, \mathrm{Ar}-\mathrm{H}) ;{ }^{13} \mathrm{C}$ NMR 53.5, 125.6, 125.9, 126.6, 129.0, 130.2, 147.8, 148.7, 155.3; MS (EI) $m / z 239$ $\left[\mathrm{M}\left({ }^{37} \mathrm{Cl}\right)+\right](34), 237\left[\mathrm{M}\left({ }^{35} \mathrm{Cl}\right)+\right](100), 177(17), 128(8), 105(55)$, 77 (59). Anal. Calcd. for $\mathrm{C}_{11} \mathrm{H}_{8} \mathrm{NO}_{3} \mathrm{Cl}$ : C, 55.60; $\mathrm{H}, 3.39 ; \mathrm{N}, 5.89$. Found: C, 55.66; H, 3.32; N, 5.92\%.

\subsubsection{Methyl 4-bromo-5-phenyl-1,3-oxazole-2-carboxylate $\mathbf{1 8}$}

Compound 18 was obtained as a solid (97\%), mp 66-68 ${ }^{\circ} \mathrm{C}$. IR (KBr) 1737, $2958 \mathrm{~cm}^{-1}$; ${ }^{1} \mathrm{H}$ NMR $4.04(3 \mathrm{H}, \mathrm{s}), 7.48-7.51(3 \mathrm{H}, \mathrm{m}$, Ar-H), 8.03-8.06 (2H, m, Ar-H); ${ }^{13} \mathrm{C}$ NMR 4.04 (3H, s), 7.48-7.51 
(3H, m, Ar-H), 8.03-8.06 (2H, m, Ar-H); MS (EI) m/z 283 [M( $\left.\left.{ }^{81} \mathrm{Br}\right)+\right]$ (100), $281\left[\mathrm{M}\left({ }^{79} \mathrm{Br}\right)+\right]$ (100), 223 (18), 221 (18), 105 (55), 77 (89). Anal. Calcd. for $\mathrm{C}_{11} \mathrm{H}_{8} \mathrm{NO}_{3} \mathrm{Br}$ : C, 46.84; H, 2.86; N, 4.97. Found: C, 47.24 ; $\mathrm{H}, 3.12$; N, 5.29\%.

\subsection{General procedure for the synthesis of 1,3-oxazoles 15 and $\mathbf{1 8}$ from haloazidoalkenes}

The azidoalkene [2b] (1 mmol) was dissolved in toluene (10 ml) and the reaction mixture was heated under reflux for $7 \mathrm{~h}$. The solvent was evaporated and the residue was washed with cooled ethyl ether giving the 1,3-oxazole as a solid.

\subsubsection{Methyl 4-chloro-5-phenyl-1,3-oxazole-2-carboxylate 15 (98\%) Identified by comparison with the specimen isolated earlier.}

\subsubsection{Methyl 4-bromo-5-phenyl-1,3-oxazole-2-carboxylate 18 (95\%) Identified by comparison with the specimen isolated earlier.}

\subsection{Methyl 4-chloro-5-phenylisoxazole-3-carboxylate $\mathbf{3 b}$}

A solution of methyl 5-phenylisoxazole-3-carboxylate $\mathbf{1 7}$ ( $70 \mathrm{mg}, 0.345 \mathrm{mmol}$ ) and NCS (85 mg, $0.64 \mathrm{mmol}$ ) in $2.3 \mathrm{~mL}$ of $7 \%$ fuming nitric acid in acetic acid was irradiated for $40 \mathrm{~min}$ in the microwave reactor (CEM Focused Synthesis System, Discover S-Class) with the temperature set to $160^{\circ} \mathrm{C}$. After cooling to room temperature, water $(15 \mathrm{~mL})$ was added and the mixture extracted with $\mathrm{CH}_{2} \mathrm{Cl}_{2}(2 \times 15 \mathrm{~mL})$. The organic phase was dried $(\mathrm{MgSO} 4)$ and evaporated off. The crude product was purified by flash chromatography [ethyl acetate-hexane (1:5)] to give $\mathbf{3 b}$ as a white solid (59\%). mp 62-63 ${ }^{\circ} \mathrm{C}$. IR (KBr) 1221, 1441, 1738, $2957 \mathrm{~cm}^{-1} ;{ }^{1} \mathrm{H}$ NMR 4.03 (3H, s), 7.52-7.55 (3H, m), 8.03-8.06 (2H, m); ${ }^{13} \mathrm{C}$ NMR 53.1, 106.0, 125.6, 126.6, 129.0, 131.2, 153.3, 159.1, 165.8; MS (EI) $m / z 237\left(\mathrm{M}^{+}, 99\right), 206$ (14), 105 (100), 77 (68), 59 (78); HRMS (CI) $\mathrm{m} / z 237.0200\left(\mathrm{C}_{11} \mathrm{H}_{8} \mathrm{NO}_{3} \mathrm{Cl}\left[\mathrm{M}^{+}\right], 237.0193\right)$.

\subsection{Infrared spectroscopy}

Matrix isolation of 1,3-oxazole 15 (MCPOC) and isoxazole $\mathbf{3 b}$ (MCPIC): The IR spectra were collected, with $0.5 \mathrm{~cm}^{-1}$ spectra resolution, using a Mattson (Infinity 60AR series) or a Nicolet 6700 Fourier transform infrared spectrometer, equipped with a deuterated triglycine sulphate (DTGS) detector and a $\mathrm{Ge} / \mathrm{KBr}$ beamsplitter.

To avoid interference from atmospheric $\mathrm{H}_{2} \mathrm{O}$ and $\mathrm{CO}_{2}$, a stream of dry nitrogen continuously purged the optical path of the spectrometers. All experiments were performed using an APD Cryogenics closed-cycle helium refrigeration system with a DE-202A expander.

To deposit the matrices, the compound to be studied was sublimated ( $T=323 \mathrm{~K}$ ) using a specially designed mini-furnace thermoelectrically heatable placed inside the cryostat and co-deposited with a large excess of the matrix gas (argon N60 obtained from Air Liquide) onto the CsI optical substrate of the cryostat cooled to $10 \mathrm{~K}$.

\subsection{Computational methodology}

The quantum chemical calculations were performed with Gaussian 03 (Revision B.01) program [10] at the DFT level of theory, using the split valence triple- $\zeta 6-311++G(d, p)$ basis set and the three-parameter B3LYP density functional, which includes Becke's gradient exchange correction [11] and the Lee, Yang and Parr correlation functional [12].

Geometrical parameters of the relevant conformations were optimized using the Geometry Direct Inversion of the Invariant
Subspace (GDIIS) method [13]. In order to assist the analysis of the experimental spectra, vibrational frequencies and IR intensities were also calculated at the same level of approximation. The computed harmonic frequencies were scaled down by two factors ( 0.9894 for MCPOC and 0.9817 for MCPIC) to correct them for the effects of basis set limitations, neglected part of electron correlation and anharmonicity effects. The optimized structures of all conformers described in this study were confirmed to correspond to true minimum energy conformations on the potential energy surface investigated.

\section{Results and discussion}

Two low energy conformers of MCPOC were predicted to exist by the calculations (Fig. 1). The IR spectrum of matrix-isolated 1,3-oxazole 15 is presented in Figs. 2 and 3 along with the calculated spectra for the two most stable conformers. The comparison of the IR spectrum of the product of the thermolysis of methyl 2benzoyl-2-chloro-2H-azirine-3-carboxylate (1b) with the theoretically predicted spectrum of MCPOC allow us to unambiguously establish the structure as being methyl 4-chloro-5-phenyl-1,3-oxazole-2-carboxylate (15).

In the present case, the formation of oxazole $\mathbf{1 5}$ from $2 \mathrm{H}$-azirine $\mathbf{1 b}$ can be explained considering the thermal cleavage of the C2-C3 to give nitrile ylide $\mathbf{1 4}$ followed by recyclization giving oxazole $\mathbf{1 5}$ as the final product (Scheme 3 ). Since the oxazole is obtained in
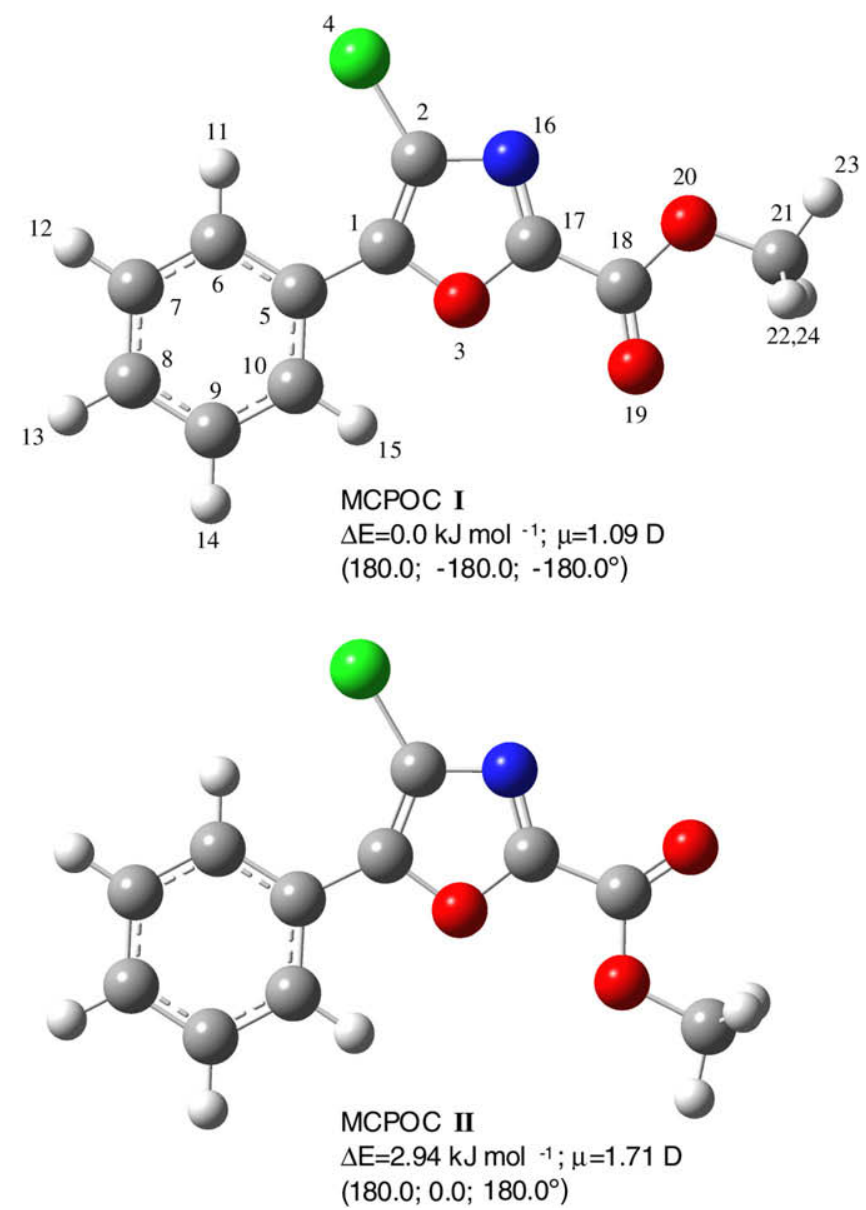

Fig. 1. Conformers of methyl 4-chloro-5-phenyl-1,3-oxazole-2-carboxylate (15) (MCPOC) with atom numbering. Relative energies and dipole moments are also provided, as well as the $\mathrm{C}_{6}-\mathrm{C}_{5}-\mathrm{C}_{1}-\mathrm{O}_{3}, \mathrm{~N}_{16}=\mathrm{C}_{17}-\mathrm{C}_{18}=\mathrm{O}_{19}$ and $\mathrm{C}_{17}-\mathrm{C}_{18}-\mathrm{O}_{20}-\mathrm{C}_{21}$ dihedral angles. 

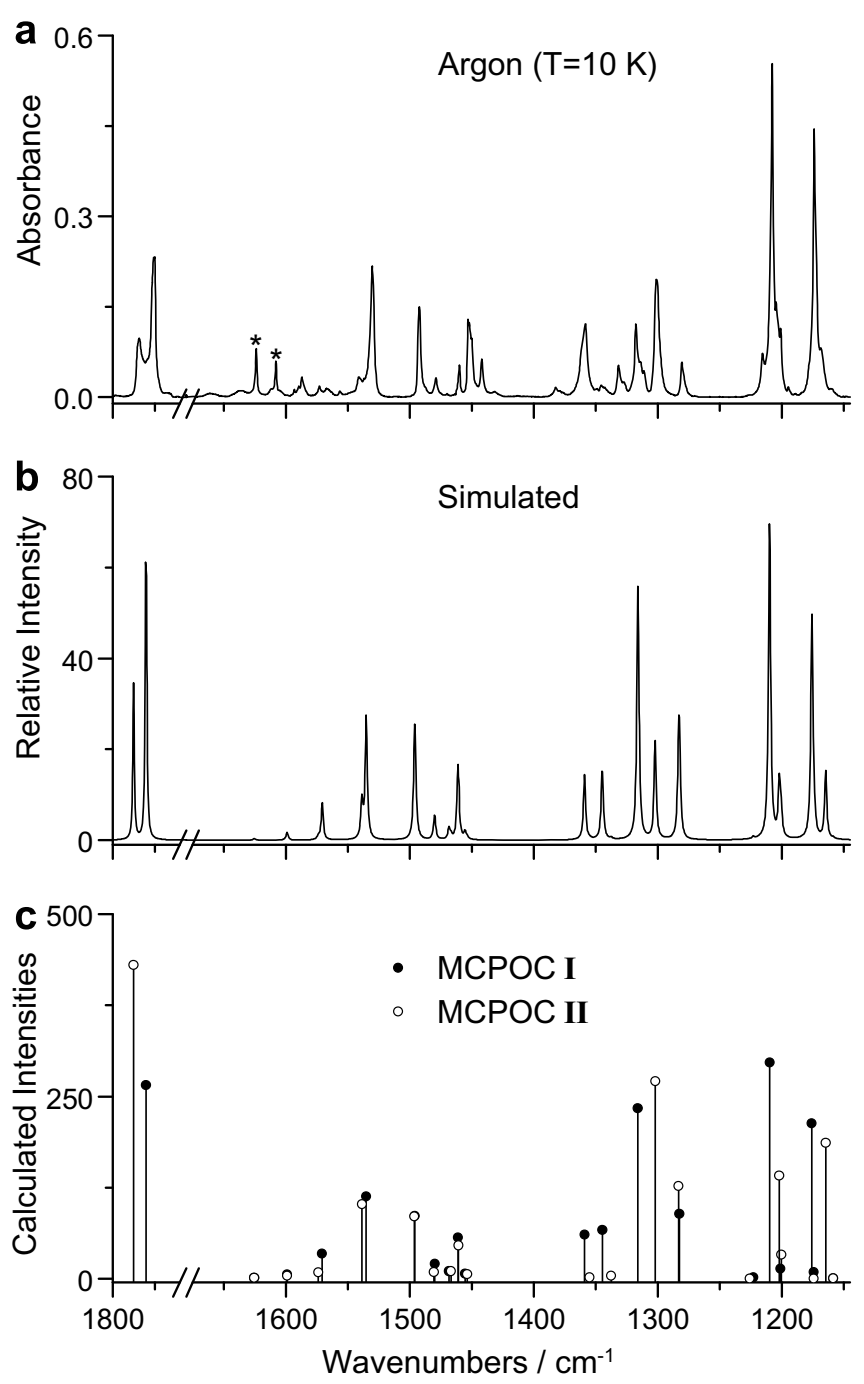

Fig. 2. Infrared spectra of MCPOC (15) $\left(1800-1145 \mathrm{~cm}^{-1}\right.$ region): (a) spectrum of MCPOC isolated in an argon matrix (sublimation temperature: $323 \mathrm{~K}$; substrate temperature: $10 \mathrm{~K}$ ), (b) simulated population-weighted (at $323 \mathrm{~K}$ ) spectrum of MCPOC using Lorentzian functions with $2 \mathrm{~cm}^{-1}$ half bandwidth and centred at the DFT(B3LYP)6-311++G(d,p) calculated wavenumbers for the two relevant conformers of MCPOC; and (c) theoretical spectra for the two conformers of MCPOC. Calculated wavenumbers were scaled by 0.9894 . Bands marked with an asterisk are due to monomeric water impurity.

high yield (98\%) we can conclude that only the reaction pathway B is observed.

Another relevant conclusion can be drawn from this study. In fact, the mechanism of formation of the $2 \mathrm{H}$-azirine ring from the haloazidoalkene $\mathbf{4 b}$ must be a concerted process since the formation of a vinylnitrene intermediate should lead to the competitive formation of the isoxazole $\mathbf{3 b}$.

Recently, $\mathrm{Li}$ et al. reported the bromination of isoxazoles with $\mathrm{N}$-bromosuccinimide in acid solvents using microwave irradiation [14]. The work included the synthesis of methyl 4-bromo-5-phenylisoxazole-3-carboxylate (3a). The authors observed that the ${ }^{13} \mathrm{C}$ NMR spectrum of this compound did not match the NMR data previously reported by us for the product of the thermolysis of 2-benzoyl-2-bromo-2H-azirine-3-carboxylate 1a [2g]. This led the authors to confirm the structure of 4-bromo-5-phenylisoxazole3-carboxylate 3a by single crystal X-ray crystallography. This was another evidence that indicates that the thermolysis of 2-benzoyl-2-halo-2H-azirine-3-carboxylates 1 leads to oxazoles and not to isoxazoles.
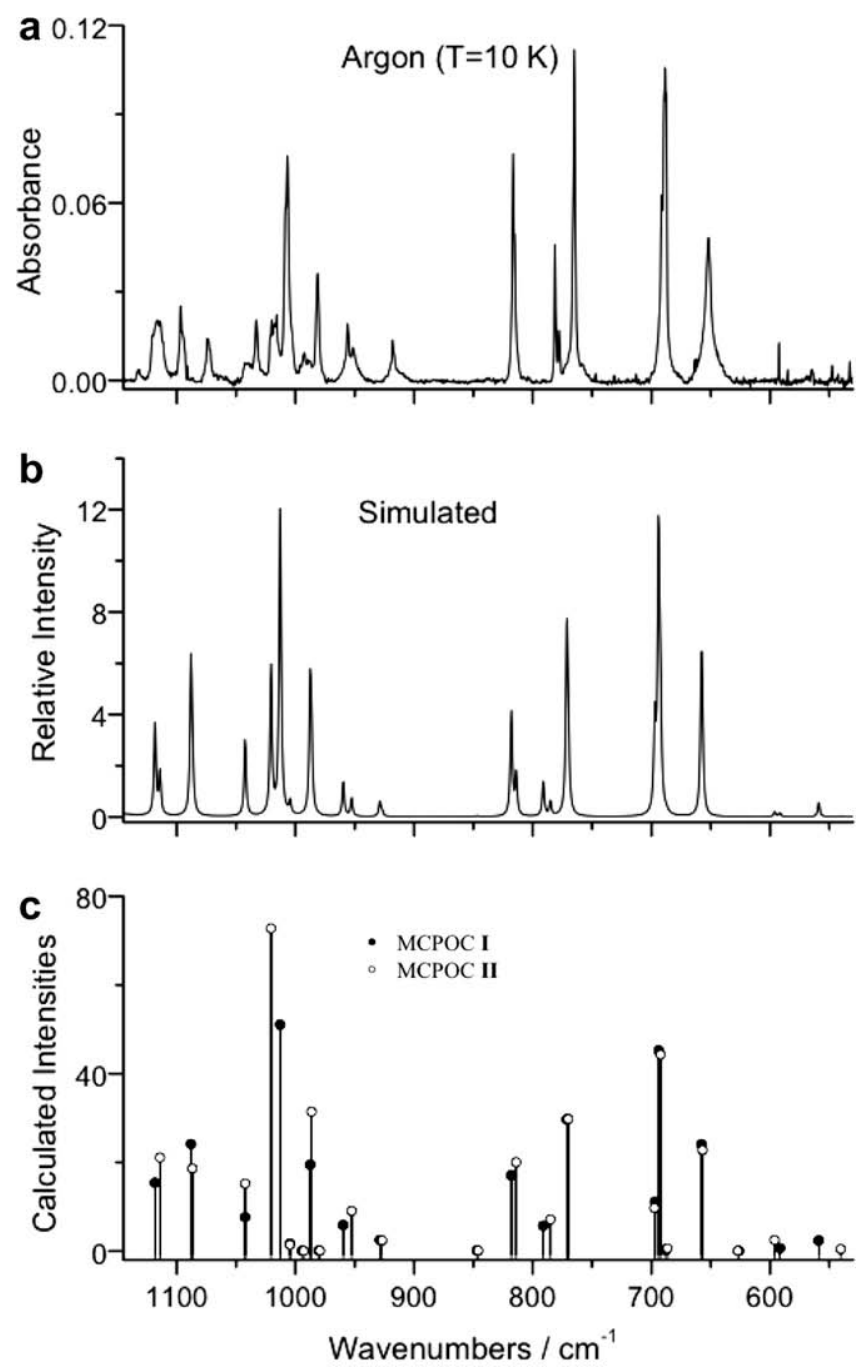

Fig. 3. Infrared spectra of $\mathrm{MCPOC} \mathrm{(15)} \mathrm{(1145-530} \mathrm{cm}^{-1}$ region): (a) spectrum of MCPOC isolated in an argon matrix (sublimation temperature: $323 \mathrm{~K}$; substrate temperature: $10 \mathrm{~K}$ ), (b) simulated population-weighted (at $323 \mathrm{~K}$ ) spectrum of MCPOC using Lorentzian functions with $2 \mathrm{~cm}^{-1}$ half bandwidth and centred at the DFT(B3LYP)6-311++G(d,p) calculated wavenumbers for the two relevant conformers of MCPOC; and (c) theoretical spectra for the two conformers of MCPOC Calculated wavenumbers were scaled by 0.9894 .

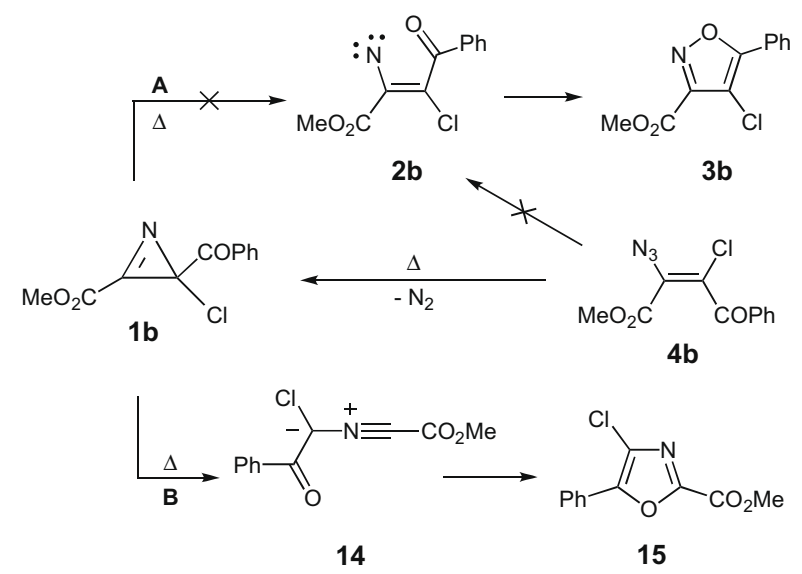

Scheme 3. 

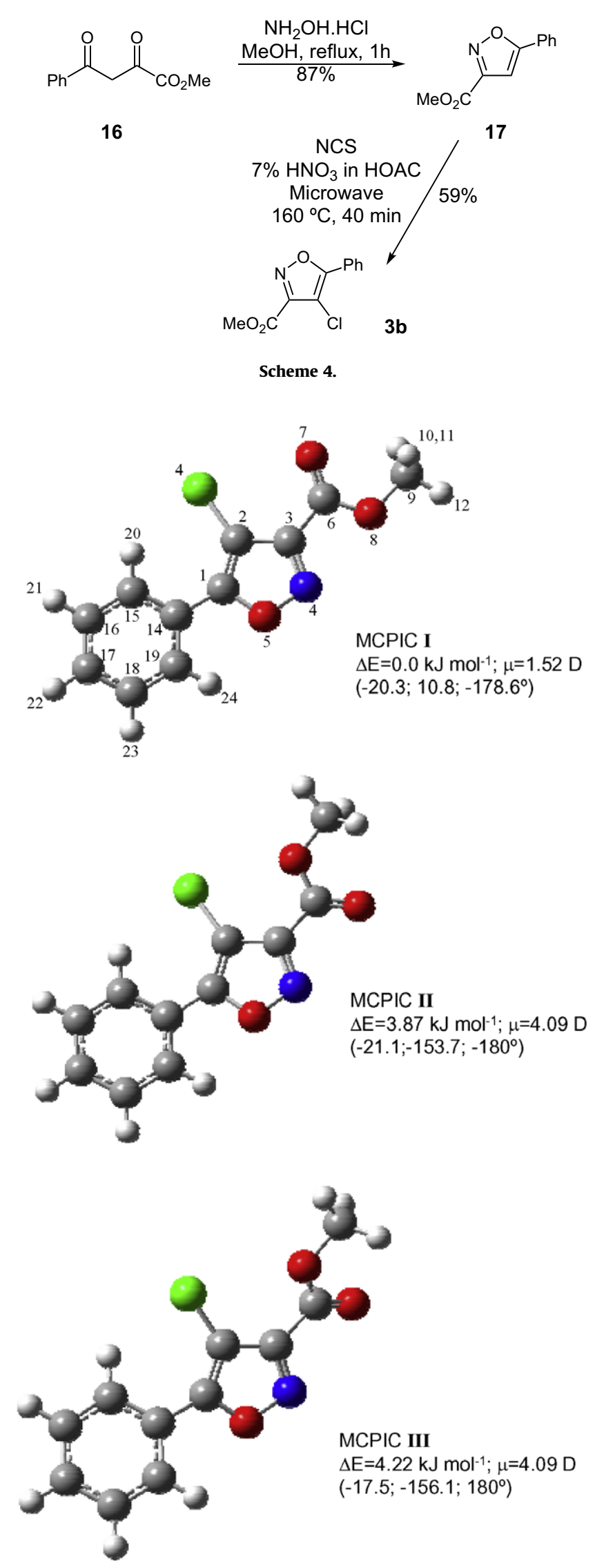

Fig. 4. Conformers of methyl 4-chloro-5-phenylisoxazole-3-carboxylate (3b) (MCPIC) with atom numbering. Relative energies and dipole moments are also provided, as well as the $\mathrm{C}_{15}-\mathrm{C}_{14}-\mathrm{C}_{1}-\mathrm{C}_{2}, \mathrm{O}_{7}=\mathrm{C}_{6}-\mathrm{C}_{3}-\mathrm{C}_{2}$ and $\mathrm{C}_{9}-\mathrm{O}_{8}-\mathrm{C}_{6}-\mathrm{C}_{3}$ dihedral angles.
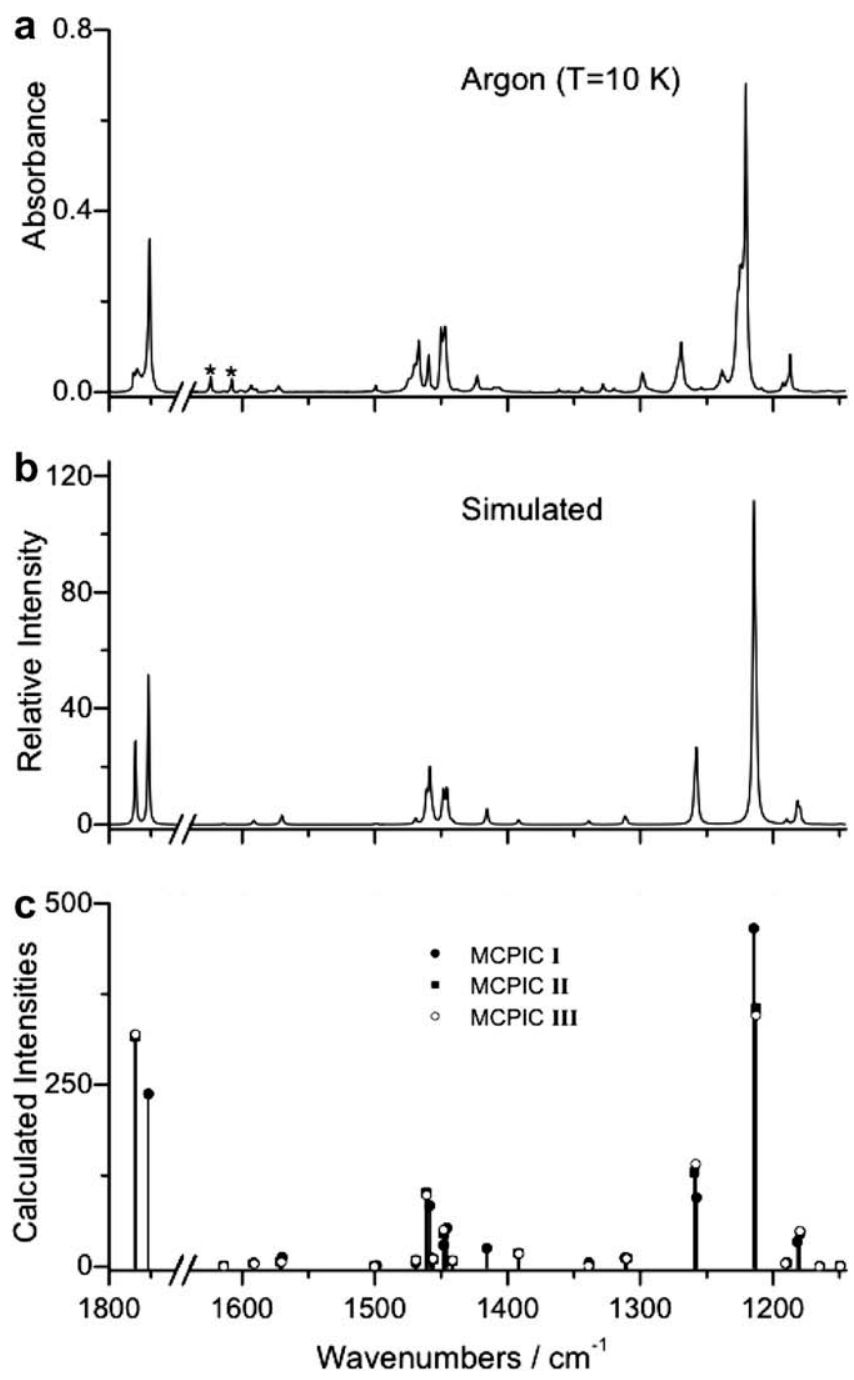

Fig. 5. Infrared spectra of MCPIC (3b) (1800-1145 $\mathrm{cm}^{-1}$ region): (a) spectrum of MCPIC isolated in an argon matrix (sublimation temperature: $323 \mathrm{~K}$; substrate temperature: $10 \mathrm{~K}$ ), (b) simulated population-weighted (at $323 \mathrm{~K}$ ) spectrum of MCPIC using Lorentzian functions with $2 \mathrm{~cm}^{-1}$ half bandwidth and centred at the DFT(B3LYP)6-311++G(d,p) calculated wavenumbers for the three relevant conformers of MCPIC; and (c) theoretical spectra of the three conformers of MCPIC. Calculated wavenumbers were scaled by 0.9817 . Bands marked with an asterisk are due to monomeric water impurity.

In order to get further support to the structural assignment we decided to prepare 4-chloro-5-phenylisoxazole-3-carboxylate $\mathbf{3 b}$ to study the compound by matrix-isolation FTIR. The synthesis of isoxazole $\mathbf{3 b}$ is outlined in Scheme 4. The starting methyl 5-phenylisoxazole-3-carboxylate (17) was prepared by cyclization of 2,4dioxo-4-phenylbutanoate (16) with hydroxylamine hydrochloride [9]. We applied the general procedure described by Li et al.[14] for the synthesis of 4-chloro-5-phenylisoxazole-3-carboxylate $\mathbf{3 b}$ but using NCS instead of NBS. Using $5 \%$ fuming nitric acid in acetic acid as solvent the solution of isoxazole $\mathbf{1 7}$ was irradiated in the microwave reactor with the temperature set to $150{ }^{\circ} \mathrm{C}$ for $25 \mathrm{~min}$ giving the desired product in $45 \%$ yield. However, the yield could be improved to $59 \%$ carrying out the microwave irradiation at $160{ }^{\circ} \mathrm{C}$ for $40 \mathrm{~min}$ and using $7 \%$ fuming nitric acid in acetic acid.

Three different low energy conformers of 4-chloro-5-phenylisoxazole-3-carboxylate $\mathbf{3 b}$ (MCPIC) were predicted to exist by the calculations (Fig. 4). The IR spectrum of matrix-isolated 4-chloro5-phenylisoxazole-3-carboxylate $\mathbf{3 b}$ (MCPIC) is shown in Figs. 5 and 6 . The assignment of the observed bands was carried out by 

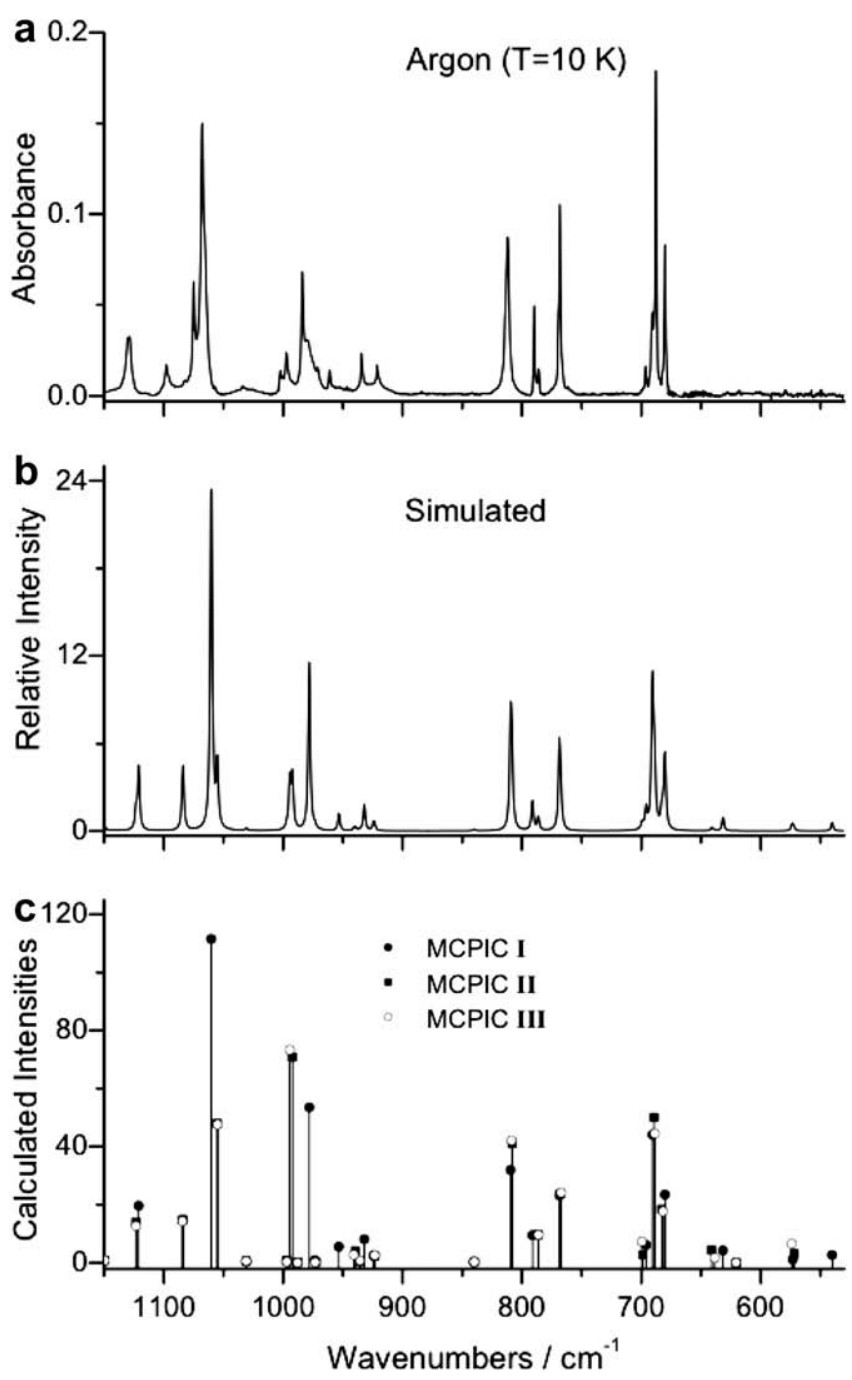

Fig. 6. Infrared spectra of MCPIC (3b) (1145-530 $\mathrm{cm}^{-1}$ region): (a) spectrum of MCPIC isolated in an argon matrix (sublimation temperature: $323 \mathrm{~K}$; substrate temperature: $10 \mathrm{~K}$ ), (b) simulated population-weighted (at $323 \mathrm{~K}$ ) spectrum of MCPIC using Lorentzian functions with $2 \mathrm{~cm}^{-1}$ half bandwidth and centred at the DFT(B3LYP)6-311++G(d,p) calculated wavenumbers of the three relevant conformers of MCPIC; and (c) theoretical spectra of the three conformers of MCPIC. Calculated wavenumbers were scaled by 0.9817 .

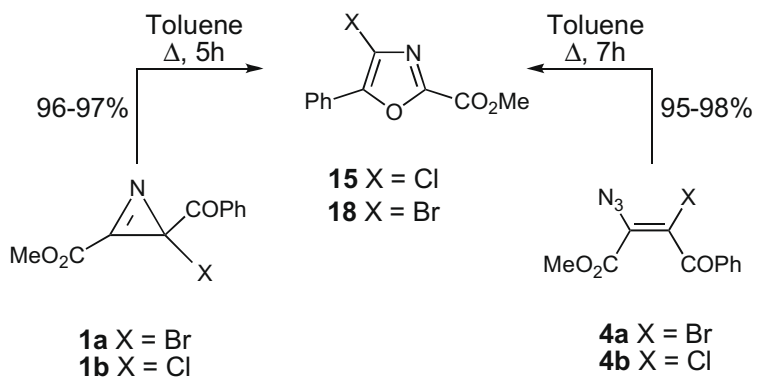

Scheme 5.

comparison with the theoretically predicted simulated spectrum, which nicely fits the observed spectrum (see Figs. 5 and 6). This spectrum of MCPIC is significantly distinct from that of the product resulting from the thermolysis of $\mathbf{1 b}$ (which, as already shown, corresponds to the 1,3-oxazole $\mathbf{1 5}$ ).
In order to give further insight into the unusual thermolysis process of the studied 2-benzoyl-2H-azirine, we now also examined the possibility of occurrence of initial formation of the isoxazole, followed by isomerization to the oxazole ring, since the thermal rearrangement of 4-acylisoxazoles to 4-acyloxazoles is known [15]. In reference [15] the synthesis of the oxazoles from the corresponding isoxazoles was rationalized considering ring contraction reaction to give a $2 \mathrm{H}$-azirine intermediate, followed by a ring expansion process via $\mathrm{C} 2-\mathrm{C} 3$ bond cleavage and cyclization. Therefore, the thermolysis of 2-benzoyl-2-chloro- $2 \mathrm{H}$-azirine-3-carboxylate $\mathbf{1 b}$ could also involve the formation of isoxazole $\mathbf{3 b}$ followed by the rearrangement to oxazole $\mathbf{1 5}$. However, this possibility was rolled out, since upon heating at reflux for $5 \mathrm{~h}$ a solution of isoxazole $\mathbf{3 b}$ in toluene no reaction was observed.

\section{Conclusion}

It is clear from the analysis of the matrix-isolated 4-chloro-5phenyl-1,3-oxazole-2-carboxylate 15 and methyl 4-chloro-5phenylisoxazole-3-carboxylate $\mathbf{3 b}$ FTIR spectra that this technique allows to distinguish easily these isomeric heterocycles. Therefore, it has been demonstrated that methyl 2-benzoyl-2-halo-2H-azirine-3-carboxylates 1 undergo thermal ring expansion to give 4halo-5-phenyl-1,3-oxazole-2-carboxylates (15 and 18) in high yield. These 1,3-oxazoles can also be obtained in high yield from haloazidoalkenes 4 (Scheme 5).

\section{Acknowledgment}

S. Lopes and C. M. Nunes acknowledge FCT for the Ph.D. Grants (SFRH/BD/29698/2006 and SFRH/BD/28844/2006).

\section{References}

[1] (a) S.A. Lang Jr., Y.-I. Lin, in: A.R. Katritzky, C.W. Rees, K.T. Potts (Eds.) Comprehensive Heterocyclic Chemistry, vol. 6, Pergamon, Oxford, 1984 (Chapter 4.16 and Chapter 4.18);

(b) T.M.V.D. Pinho e Melo, Curr. Org. Chem. 9 (2005) 925;

(c) V.S.C. Yeh, Tetrahedron 60 (2004) 11995;

(d) Y. Hamada, T. Shioiri, Chem. Rev. 105 (2005) 4441;

(e) P. Wipf, Chem. Rev. 95 (1995) 2115.

[2] (a) T.M.V.D. Pinho e Melo, C.S.J. Lopes, A.M.d'A. Rocha Gonsalves, Tetrahedron Lett. 41 (2000) 7217;

(b) T.M.V.D. Pinho e Melo, C.S.J. Lopes, A.L. Cardoso, A.M.d'A. Rocha Gonsalves, Tetrahedron 57 (2001) 6203;

(c) T.M.V.D. Pinho e Melo, C.S.J. Lopes, A.M.d'A. Rocha Gonsalves, A.M. Beja, J.A Paixão, M.R. Silva, L.A. Veiga, J. Org. Chem. 67 (2002) 66;

(d) T.M.V.D. Pinho e Melo, A.L. Cardoso, C.S.B. Gomes, A.M.d'A. Rocha Gonsalves, Tetrahedron 59 (2003) 2345;

(e) T.M.V.D. Pinho e Melo, Cardoso, A.L. Cardoso, C.S.B. Gomes, A.M.d'A. Rocha Gonsalves, Tetrahedron Lett. 44 (2003) 6313;

(f) T.M.V.D. Pinho e Melo, A.M.d'A. Rocha Gonsalves, Curr. Org. Synth. 1 (2004) 275;

(g) T.M.V.D. Pinho e Melo, C.S.J. Lopes, A.M.d'A. Rocha Gonsalves, R.C. Storr, Synthesis (2002) 605;

(h) S.M. Fonseca, H.D. Burrows, C.M. Nunes, T.M.V.D. Pinho e Melo, A.M.d'A. Rocha Gonsalves, Chem. Phys. Lett. 414 (2005) 98.

[3] F. Palacios, A.M.O. Retana, E.M. Marigorta, J.M. Santos, Eur. J. Org. Chem. (2001) 2401.

[4] T. Nishiwaki, J. Chem. Soc. Chem. Comm. (1972) 565.

[5] (a) A. Padwa, J. Smolanoff, A. Tremper, J. Am. Chem. Soc. 97 (1975) 4682;

(b) A. Padwa, T. Stengel, Tetrahedron Lett. 45 (2004) 5991;

(c) B. Singh, E.F. Ullman, J. Am. Chem. Soc. 89 (1967) 6911;

(d) G. L'abbé, Angew. Chem. Inter. Ed. 14 (1975) 775;

(e) K. Friedrich, H.K. Thieme, Chem. Ber. 103 (1970) 1982;

(f) A. Hassner, G. L'abbé, M.J. Miller, J. Am. Chem. Soc. 93 (1971) 981.

[6] (a) A. Gómez-Zavaglia, A. Kaczor, A.L. Cardoso, T.M.V.D. Pinho e Melo, R. Fausto, J. Phys. Chem. A 110 (2006) 8081;

(b) A. Kaczor, A. Gómez-Zavaglia, A.L. Cardoso, T.M.V.D. Pinho e Melo, R. Fausto, J. Phys. Chem. A 110 (2006) 10742;

(c) A. Gómez-Zavaglia, A. Kaczor, A.L. Cardoso, T.M.V.D. Pinho e Melo, R. Fausto, J. Mol. Struct. 834-835 (2007) 262;

(d) H. Inui, S. Murata, Chem. Phys. Lett. 359 (2002) 267;

(e) H. Inui, S. Murata, J. Am. Chem. Soc. 127 (2005) 2628. 
[7] (a) K. Isomura, Y. Hirose, H. Shuyama, S. Abe, G. Ayabe, H. Taniguchi, Heterocycles 9 (1978) 1207;

(b) S. Brahma, J.K. Ray, J. Heterocycl. Chem. 45 (2008) 311.

[8] R. Wingen, D. Guenther, J. Lignau, Ger. Offen. DE 3.706,881; Chem. Abstract, 110 (1989) 125315

[9] (a) C. Maurion, F. Bailly, P. Cotelle, Tetrahedron 60 (2004) 6479; (b) A.K. Roy, S. Batra, Synthesis 15 (2003) 2325.

[10] M.J. Frisch, G.W. Trucks, H.B. Schlegel, G.E. Scuseria, M.A. Robb, J.R. Cheeseman, J.A. Montgomery Jr., T. Vreven, K.N. Kudin, J.C. Burant, J.M Millam, S.S. Iyengar, J. Tomasi, V. Barone, B. Mennucci, M. Cossi, G. Scalmani, N. Rega, G.A. Petersson, H. Nakatsuji, M. Hada, M. Ehara, K. Toyota, R. Fukuda, J. Hasegawa, M. Ishida, T. Nakajima, Y. Honda, O. Kitao, H. Nakai, M. Klene, X. Li, J.E. Knox, H.P. Hratchian, J.B. Cross, V. Bakken, C. Adamo, J. Jaramillo, R. Gomperts, R.E. Stratmann, O. Yazyev, A.J. Austin, R.
Cammi, C. Pomelli, J.W. Ochterski, P.Y. Ayala, K. Morokuma, G.A. Voth, P. Salvador, J.J. Dannenberg, V.G. Zakrzewski, S. Dapprich, A.D. Daniels, M.C. Strain, O. Farkas, D.K. Malick, A.D. Rabuck, K. Raghavachari, J.B. Foresman, J.V. Ortiz, Q. Cui, A.G. Baboul, S. Clifford, J. Cioslowski, B.B. Stefanov, G. Liu, A. Liashenko, P. Piskorz, I. Komaromi, R.L. Martin, D.J. Fox, T. Keith, M.A. AlLaham, C.Y. Peng, A. Nanayakkara, M. Challacombe, P.M.W. Gill, B. Johnson, W. Chen, M.W. Wong, C. Gonzalez, J.A. Pople, Gaussian 03, revision B.01; Gaussian, Inc.: Wallingford, CT, (2004).

[11] A.D. Becke, Phys. Rev. A 38 (1988) 3098.

[12] C.T. Lee, W.T. Yang, R.G. Parr, Phys. Rev. B 37 (1988) 785.

[13] P. Csaszar, P. Pulay, J. Mol. Struct. (Theochem.) 114 (1984) 31.

[14] G. Li, R. Kakarla, S.W. Gerritz, Tetrahedron Lett. 48 (2007) 4595.

[15] (a) A. Padwa, E. Chen, J. Org. Chem. 39 (1974) 1976;

(b) A. Padwa, E. Chen, A. Ku, J. Am. Chem. Soc. 97 (1975) 6484. 